\title{
THEORETICAL INVESTIGATION ON THE SEAKEEPING PERFORMANCE OF A SUPPLY VESSEL WITH X-BOW
}

\author{
Dan Obreja \\ "Dunarea de Jos" University of Galati, \\ Faculty of Naval Architecture, Galati, \\ Domneasca Street, No. 47, 800008, Romania, \\ E-mail:dan.obreja@ugal.ro
}

\author{
Mădălina Dajbog \\ "Dunarea de Jos" University of Galati, \\ Faculty of Naval Architecture, Galati, \\ Domneasca Street, No. 47, 800008, Romania, \\ E-mail: dajbog.madalina@yahoo.com
}

\begin{abstract}
The X-bow concept was developed by Ulstein company, in order to increase the ship hydrodynamic performance. Low resistance, reduced fuel consumption, smoother motion and low acceleration levels are some of the hydrodynamics improvements. A theoretical analysis on the seakeeping performance of a supply vessel with X-bow form was performed by using Aveva Marine Engineering Software and it is presented in this paper. The ship motions and accelerations on irregular waves were calculated and the influence of the roll gyradius and bilge keel was analysed. The conclusion reveals the important influence of the mentioned elements on the ship motions and accelerations.
\end{abstract}

Keywords: X-bow supply vessel, seakeeping performance, theoretical estimation

\section{INTRODUCTION}

The hydrodynamic safety of a ship running in waves field with a given speed represents a main component of the global security concept. Its evaluation is based on the seakeeping performance analysis in dangerous conditions.

The complexity of the theoretical approach on this topic is generated by the coupled motions of the ship with six degrees of freedom. The estimation of the ship motions and accelerations with a satisfactory accuracy level is necessary. For this purpose, different CAD-CAE systems can be used.

This paper presents a theoretical analysis on the seakeeping performance of a supply vessel with X-bow form which was performed by using Aveva Marine Engineering Software.

The X-bow concept was developed by Ulstein company, in order to increase the ship's hydrodynamic performance. Low resistance, reduced fuel consumption, smoother motion and low acceleration levels are some of the hydrodynamics improvements reported by Ulstein in the case of X-bow concept.

The main characteristics of the supply vessel are presented in Table 1.

Table 1. Main characteristics of the supply vessel

\begin{tabular}{|l|c|}
\hline \multicolumn{1}{|c|}{ Main characteristics } & $\begin{array}{c}\text { Full } \\
\text { scale }\end{array}$ \\
\hline \hline Length overall, $L_{O A}[\mathrm{~m}]$ & 83.3 \\
\hline Length of waterline, $L_{W}[\mathrm{~m}]$ & 79.5 \\
\hline Length between perpendiculars, $L_{B P}[\mathrm{~m}]$ & 82.3 \\
\hline Beam, $B[\mathrm{~m}]$ & 18.0 \\
\hline Depth, $D[\mathrm{~m}]$ & 20.3 \\
\hline Draft, $T[\mathrm{~m}]$ & 6.0 \\
\hline Longitudinal center of buoyancy, $L C B[\mathrm{~m}]$ & 37.203 \\
\hline Volumetric displacement, $\nabla\left[\mathrm{m}^{3}\right]$ & 5755.1 \\
\hline Design speed, $v[\mathrm{~m} / \mathrm{s}]$ & 15.0 \\
\hline Froude number, $F_{n}$ & 0.276 \\
\hline Block coefficient, $C_{B}$ & 0.646 \\
\hline Waterplane coefficient, $C_{W}$ & 0.827 \\
\hline Midship section coefficient, $C_{M}$ & 0.985 \\
\hline \hline
\end{tabular}


The transverse sections of the body lines plan are presented in Fig. 1.

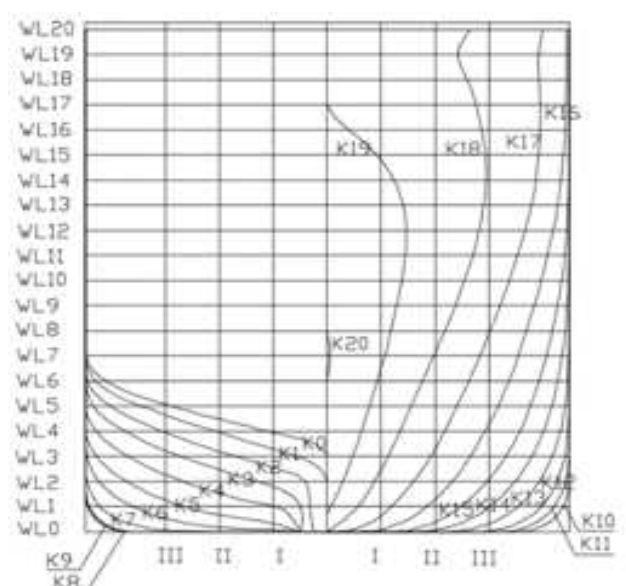

Fig. 1. Transverse sections of the supply vessel

A summary of the theoretical model, applied in this paper, in order to calculate the seakeeping performance of the supply vessel is presented in the next chapter.

\section{THEORETICAL METHODOLOGY}

The ship's motion equations on the incident waves can be written by using Newton's second law

$$
\frac{d}{d t}(M \cdot \dot{\eta})=H
$$

where $M$ is the matrix of the masses and inertia moments of the ship, $\eta$ is the ship motion and $H$ represents the hydrodynamic forces and moments.

Under the linear hydrodynamic model assumption, the following relation can be written

$$
H=F_{E}+G_{R}
$$

where $F_{E}$ are the excitation forces and moments generated by the incident waves and $G_{R}$ are the radiation forces and moments given by the relation [3]

$$
G_{R}=-A \cdot \ddot{\eta}-B \cdot \dot{\eta}-C \cdot \eta
$$

The matrix A is the added masses matrix, B is the potential damping coefficients matrix and $\mathrm{C}$ is the restoring coefficients matrix.

The added masses and damping coefficients can be calculated on the basis of the sources distribution method, suggested by Frank [2].

The general form of the ship motion equations is obtained by replacing the expressions (2) and (3) in relation (1)

$$
(M+A) \ddot{\eta}+B \dot{\eta}+C \eta=F_{E}
$$

The response amplitudes operators of the ship's motion $R A O_{\eta}$ and accelerations $R A O_{a}$ can be determined on the basis of the solution of the system (4)

$$
\begin{aligned}
& R A O_{\eta}=\left(\frac{\eta}{\zeta_{w}}\right)^{2} \\
& R A O_{a}=\left(\frac{a}{\zeta_{w}}\right)^{2}
\end{aligned}
$$

where $\zeta_{w}$ is the regular wave amplitude and $a$ is the ship acceleration.

For a given sea state with power spectral density $S_{w}$, the response spectra of the motions $S_{\eta}$ and accelerations $S_{a}$ can be calculated with the expressions [1]

$$
\begin{aligned}
& S_{\eta}\left(\omega_{e}\right)=R A O_{\eta} \cdot S_{w}\left(\omega_{e}\right) \\
& S_{a}\left(\omega_{e}\right)=R A O_{a} \cdot S_{w}\left(\omega_{e}\right)
\end{aligned}
$$

where $\omega_{e}$ represents the encountering circular frequency.

Based on the mentioned response spectra, the spectra moments of zero order for motions $m_{0}^{\eta}$ and accelerations $m_{0}^{a}$ can be calculated by using the relations

$$
\begin{aligned}
& m_{0}^{\eta}=\int_{0}^{\infty} S_{\eta}\left(\omega_{e}\right) \cdot d \omega_{e} \\
& m_{0}^{a}=\int_{0}^{\infty} S_{a}\left(\omega_{e}\right) \cdot d \omega_{e}
\end{aligned}
$$


Also, the root mean square values of the amplitudes of the ship's motions $R M S_{\eta}$ and accelerations $R M S_{a}$ on irregular waves can be evaluated by using the expressions

$$
\begin{aligned}
& R M S_{\eta}=\sqrt{m_{0}^{\eta}} \\
& R M S_{a}=\sqrt{m_{0}^{a}}
\end{aligned}
$$

Specific criteria based on RMS values were adopted for the ship motions and accelerations:

- Roll motion, $R M S_{\Phi}=8$ deg.;

- Pitch motion, $R M S_{\theta}=3$ deg.;

- Lateral acceleration, $R M S_{a y}=2 \mathrm{~m} / \mathrm{s}^{2}$;

- Vertical acceleration $R M S_{a z}=4 \mathrm{~m} / \mathrm{s}^{2}$.

Based on the specific criteria, the polar diagrams can be obtained, in order to determine the influence of the speed and shipwave incident angle on the seakeeping performance, for a given sea state.

\section{PRACTICAL EVALUATION}

The ITTC spectrum was selected in order to analyse the seakeeping performance of the supply vessel, on irregular waves with significant height $H_{w}$ of $1 \mathrm{~m}, 1.5 \mathrm{~m}$ and $2 \mathrm{~m}$.

The lateral and vertical accelerations were calculated in a point situated on the transvers section of the forward perpendicular, on the main deck edge.

The specific criteria for roll and pitch motions were fulfilled for the considered sea states (Fig. 2).

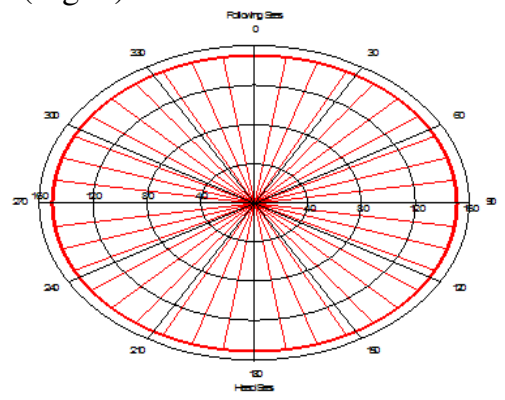

Fig. 2. Polar diagram. Roll and pitch motions
In the case of lateral acceleration, the mentioned criterion was not fulfilled for quartering and beam waves, with significant height greater then $1 \mathrm{~m}$ (Figs. 3 and 4).

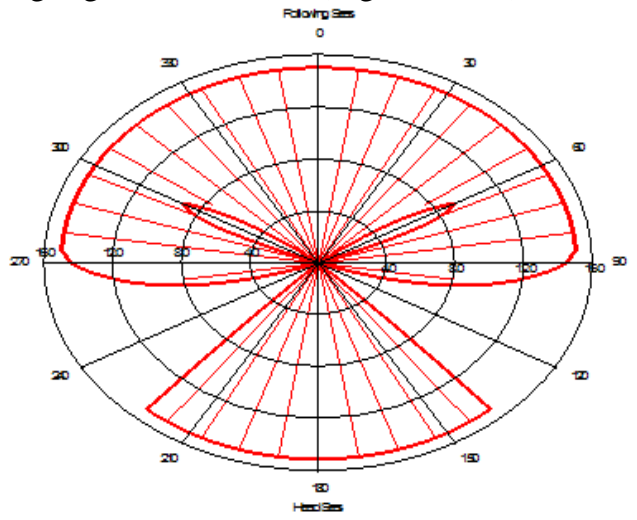

Fig. 3. Polar diagram. Lateral acceleration for $H_{w}=1.5 \mathrm{~m}$

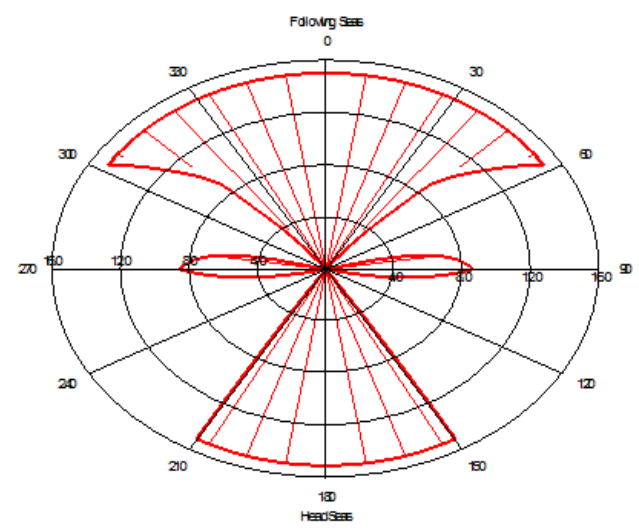

Fig. 4. Polar diagram. Lateral acceleration for $H_{w}=2 \mathrm{~m}$

Also, the specific criterion was not fulfilled in the case of vertical acceleration (Figs. 5 and 6), in principal for head waves and fore quartering waves, with significant height exceeding $1 \mathrm{~m}$.

The changing of the speed or ship-wave incident angle represents solutions to avoid the critical domains.

The influence of the roll gyradius on the roll motion was analysed. The values of the nondimensional roll gyradius were adopted in the domain $0.2 \quad \ldots 0.4$ with step of 0.05 and their influence on the $R M S_{\Phi}$ function 
was established. The nondimensional roll gyradius was calculated by means of the roll gyradius over beam ratio.

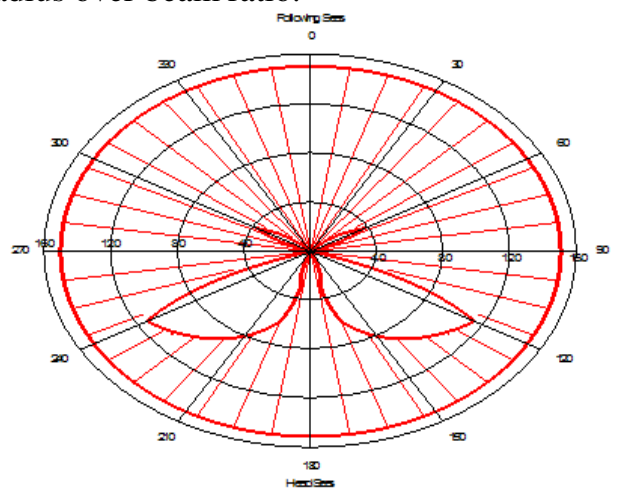

Fig. 5. Polar diagram. Vertical acceleration for $H_{w}=1.5 \mathrm{~m}$

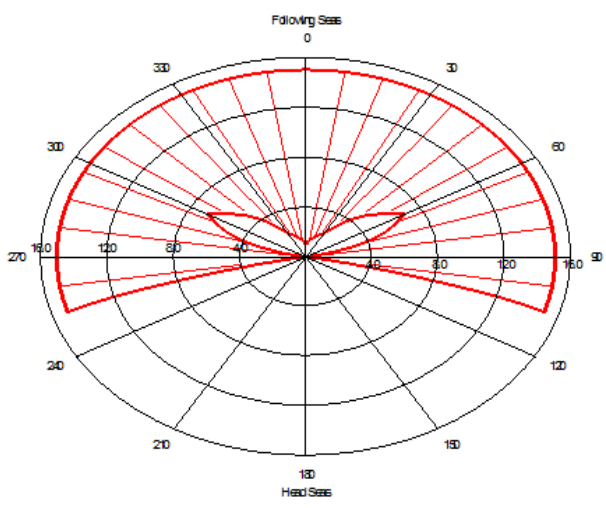

Fig. 6. Polar diagram. Vertical acceleration for $H_{w}=2 \mathrm{~m}$

Figs. 7 and 8 depict the diagrams of the $R M S_{\Phi}$ function depending by the ship-wave incident angle $\mu$ and the nondimensional roll gyradius $r x x$, at zero and design speeds respectively, on irregular waves with significant height $H_{w}=2 \mathrm{~m}$.

If the roll gyradius increases, the $R M S_{\Phi}$ function decreases at zero speed. In the case of the design speed, the maximum values of the $R M S_{\Phi}$ function depend on the ship-wave incident angle. If $r x x=0.3$ and $\mu=60^{\circ}$, the maximum value is obtained. On beam, fore quartering waves or head waves, the $R M S_{\Phi}$ function decreases if the roll gyradius increases.
A similar analysis was performe on the influence of the roll gyradius related to the lateral acceleration $R M S_{a y}$ and vertical acceleration $R M S_{a z}$. Figs. 9, 10, 11 and 12 illustrate the variation of the $R M S_{a y}$ and $R M S_{a z}$ functions, on irregular waves with significant height $H_{w}=2 \mathrm{~m}$, depending by the ship-wave incident angle $\mu$ and the nondimensional roll gyradius $r x x$, both at zero and design speeds.

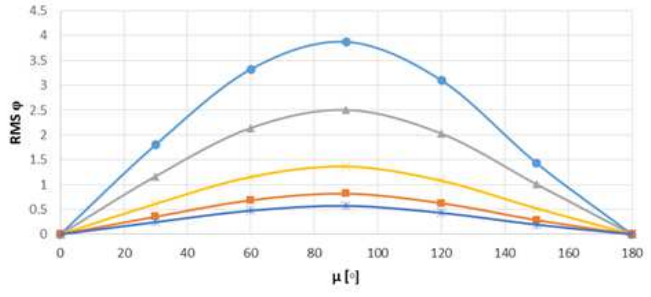

Fig. 7. $R M S_{\Phi}$ function at zero speed, for

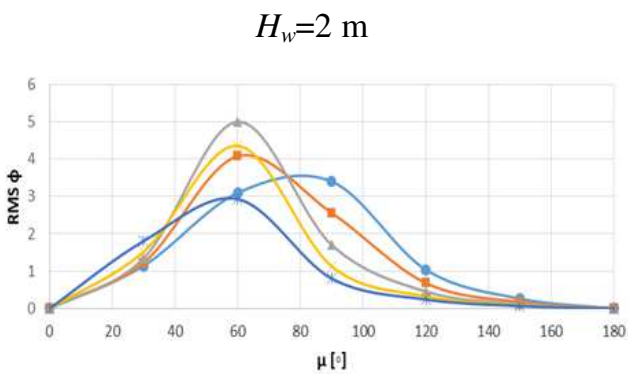

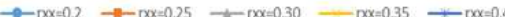

Fig. 8. $R M S_{\Phi}$ function at design speed, for

$$
H_{w}=2 \mathrm{~m}
$$

In the case of zero speed, two maximum values were observed for $R M S_{a y}$ and $R M S_{a z}$ functions, for ship-wave incident angle $\mu$ having the values $60^{\circ}$ and $120^{\circ}$ respectively. In the case of design speed, only one maximum value was obtained, when $\mu=120^{\circ}$ for $R M S_{a y}$ and when $\mu=150^{\circ}$ for $R M S_{a z}$.

The maximum values at zero and design speeds were obtained for the $R M S_{a y}$ function when the nondimensional roll gyradius $r x x=0.4$. For the $R M S_{a z}$ function, when $r x x=0.2$ the maximum values were obtained. 


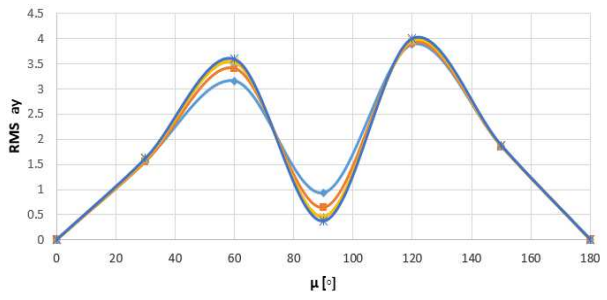

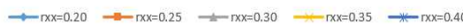

Fig. 9. $R M S_{a y}$ function at zero speed, for

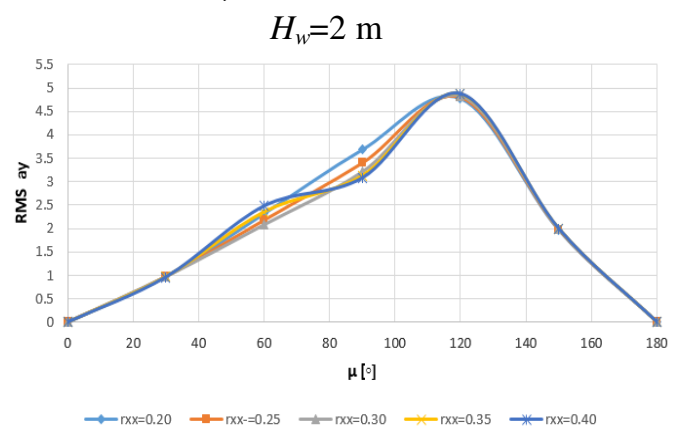

Fig. 10. $R M S_{a y}$ function at design speed, for

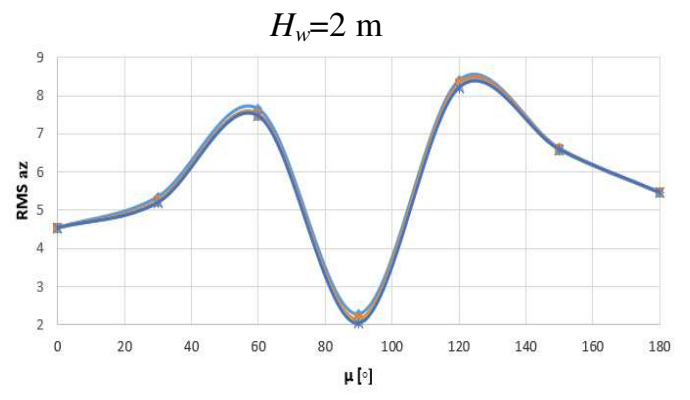

Fig. 11. $R M S_{a z}$ function at zero speed, for

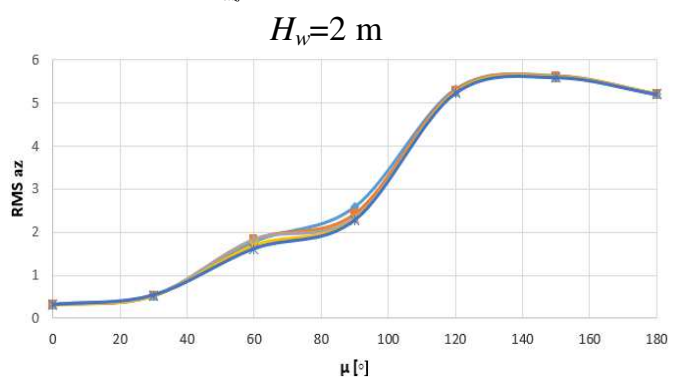

Fig. 12. $R M S_{a z}$ function at design speed, for

$$
H_{w}=2 \mathrm{~m}
$$

The influence of the bilge keel on the roll motion was analysed in the final part of this study. The beam of the bilge keel was modified in the range $0.2 \mathrm{~m} \ldots 0.6 \mathrm{~m}$, with step of $0.1 \mathrm{~m}$ and the length of the bilge keel was equal with $0.7 \mathrm{~L}_{\mathrm{W}}=55.67 \mathrm{~m}$.

Figs. 13 and 14 present the diagrams of the $R M S_{\Phi}$ function depending by the shipwave incident angle $\mu$ and the beam of the bilge keel, in the critical case with the nondimensional roll gyradius $r x x=0.2$, on irregular waves with significant height $H_{w}=2$ $\mathrm{m}$, at zero and design speeds respectively.

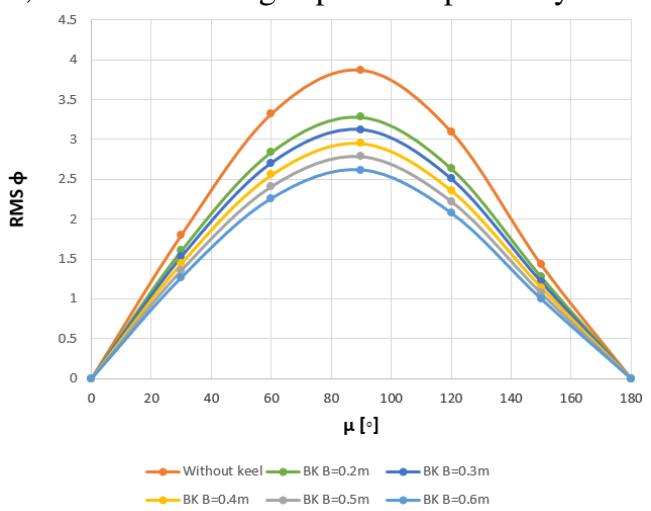

Fig. 13. $R M S_{\Phi}$ function at zero speed, with bilge keel influence, for $H_{w}=2 \mathrm{~m}$ and $r x x=0.2$

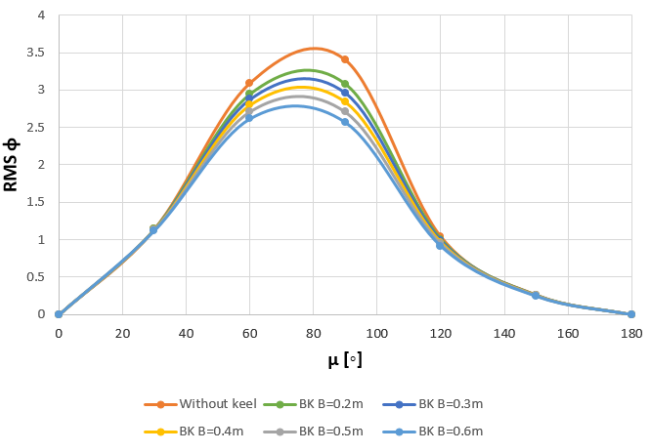

Fig. 14. $R M S_{\Phi}$ function at design speed, with bilge keel influence, for $H_{w}=2 \mathrm{~m}$ and $r x x=0.2$

An important contribution on the roll damping can be observed at zero and design speeds, due to the bilge keel.

If the beam of the bilge keel increases, the $R M S_{\Phi}$ function of the roll motion decreases. 


\section{CONCLUDING REMARKS}

The evaluation of the hydrodynamic safety of a ship running in waves field with a given speed is based on the seakeeping performance analysis in dangerous conditions.

A theoretical investigation on the seakeeping performance of a supply vessel with $\mathrm{X}$-bow form was performed in this paper, on irregular waves with significant height equal with $1 \mathrm{~m}, 1.5 \mathrm{~m}$ and $2 \mathrm{~m}$, by using Aveva Marine Engineering Software.

The ship's accelerations were calculated on the main deck edge, in the transvers section of the forward perpendicular.

The X-bow concept was proposed by Ulstein company, in order to increase the hydrodynamic performance, the ship motions and accelerations included.

The adopted criteria for roll and pitch motions were fulfilled for all sea states. According with the Ulstein concept, the moderate amplitudes of the motions for supply vessel were determined.

In the case of vertical and lateral accelerations, restricted navigation area in the polar plots were identified, for waves significant height exceeding $1 \mathrm{~m}$.

The influences of the roll gyradius and bilge keels on the roll motion were analysed.

If the roll gyradius increases, the $R M S_{\Phi}$ function decreases both at zero speed and design speed, on beam or fore quartering waves. If $\mu=60^{\circ}$ and $r x x=0.3$, a maximum value of the $R M S_{\Phi}$ function was obtained at the design speed.

Also, an important influence of the bilge keel was demonstrated, in the critical case when the nondimensional roll gyradius has the value $r x x=0.2$, on irregular waves with the significant height $H_{w}=2 \mathrm{~m}$, at zero and design speeds respectively.

All these theoretical results must be validated on the basis of experimental model tests.

\section{Acknowledgements}

The research was supported by the Naval Architecture Faculty, in "Dunarea de Jos" University of Galati, which is greatly acknowledged.

\section{REFERENCES}

[1]. Bhattacharyya, R., "Dynamic of $M a$ rine Vehicles", John Wiley \& Sons, New York, 1987.

[2]. W. Frank, "Oscillation of Cylinders in or Below the Free Surface of Deep Fluids", NSRDC Washington, Report No. 2375, 1967.

[3]. Salvesen, N., Tuck, E.O., Faltinsen, O., "Ship Motions and Sea Loads", Transactions of SNAME, New York, pp. 250-279, 2000.

Paper received on December $14^{\text {th }}, 2018$ 